\title{
ACCURACY CHARACTERISTICS OF RADIO MONITORING ANTENNAS
}

Shcherbyna O. A. - PhD, Associate Professor of the Department of Electronics, Robotics and Technology of Monitoring and Internet of Things, National Aviation University, Kyiv, Ukraine.

Ilnitskyi L. Ya. - Dr. Sc., Honored Worker of Science and Technology of Ukraine, National Aviation University, Kyiv, Ukraine.

Mykhalchuk I. I. - Professor Assistant of the Department of Electronics, Robotics and Technology of Monitoring and Internet of Things, National Aviation University, Kyiv, Ukraine.

Kozhokhina O. V. - PhD, Associate Professor of the Department of Avionics, National Aviation University, Kyiv, Ukraine.

\section{ABSTRACT}

Context. The constant increase in the number of radio electronic equipment leads to an ever-increasing complication of the electromagnetic environment. That requires constant monitoring to ensure electromagnetic compatibility, as well as the development of high-quality universal antennas for radio monitoring systems.

Objective. The goal of the work is construction of a mathematical model of an antenna system for radio monitoring stations and calculation of its main accuracy characteristics.

Method. The most important metrological characteristics of a measuring instrument are methodical and instrumental errors, that is, the dependence of these errors on the parameters of structural elements of the signal processing device, which is integrated with the antenna array. Consequently, the mathematical model of the antenna system should take into account not idealized, but real transmission coefficients of the most critical structural components. Besides, to ensure transparent functional relations between the voltages in the mathematical model is necessary to limit the number of variables informative voltages. With this approach, the determination of instrumental errors is greatly simplified, and analytical expressions become more suitable for assessing the influence of structural elements on the accuracy of measuring processes.

Results. Analytical relations were obtained that reveal the influence of different elements and circuits of the device on the measurement accuracy of the radiation fields parameters.

Conclusions. The present findings confirm that the presented antenna system provides a measurement of the main parameters of the radiation field both in the conditions of a satisfactory electromagnetic environment. Moreover, in the conditions when another frequency of radiation acts at the frequency of the useful signal. The angular resolution, that is, the ability to separate signals with an insignificant angular spacing of signal sources and interference, depends not only on the directivity characteristics of the antenna array but also on the accuracy of establishing the distances between the phase centres of real and virtual vibrators. The operating frequency range of the antenna array is limited not only by the deformation of the radiation pattern as well by the errors in the design of the antenna structural elements.

KEYWORDS: radio monitoring systems, antenna array, accuracy characteristics, methodical errors, instrumental errors.

\section{ABBREVIATIONS}

AFC is an amplitude-phase corrector;

AFTU is an amplification and frequency transformation unit;

BNT is a block of nonlinear transformations;

COU is a controlled oscillator unit;

DDRS is a device of display and recording signals;

DIRS is a device for indication and registration of signals;

EMC is electromagnetic compatibility;

EMRD is an electromechanical rotary device;

ID is an identification device;

$\mathrm{LC}$ is a linear converter;

MT is a measuring transducer;

RMS is a root-mean-square;

SCU is a switch control unit;

SID is a signal identification device;

TVG is a test voltage generator.

\section{NOMENCLATURE}

$a$ is a transmission coefficient of frequency converters and amplifiers of intermediate frequency;

$d$ is a distance between phase centers of antenna elements;

$d_{s c}$ is a distance from the screen to antenna
$\mathbf{E}_{a}, \mathbf{E}_{b}$ are vectors of field intensities from sources $a$ and $b$

$F(\theta, \varphi)$ is a directivity characteristic;

$k$ is a wave number;

$K$ is a transmission coefficient from vibrator terminals to the input terminals of frequency converters;

$k_{a}, k_{b}$ are wave numbers for the waves of sources $a$ and $b$;

$K_{\varphi_{1}}^{a}$ is a sensitivity factor of the voltage $U_{1}^{a}$ to azimuth error of the source $b$;

$K_{d_{1}}^{a}$ is a sensitivity coefficient of the voltage $U_{1}^{a}$ the estimation error of the distanced between the phase centers of vibrators;

$K_{s c_{1}}^{a}$ is a sensitivity coefficient of the voltage $U_{1}^{a}$ to the estimation error of the distance $d_{s c}$ between the phase centers of vibrators and screen;

$K_{\theta_{1}}^{b}$ is a sensitivity factor of the voltage $U_{1}^{b}$ to inaccurate setting of the angle $\theta_{a}=90^{\circ}$; elements; 
$K_{\varphi_{1}}^{b}$ is a sensitivity factor of the voltage $U_{1}^{b}$ to the error in the azimuth of the source $b$;

$K_{s c_{1}}^{b}$ is a sensitivity coefficient of the voltage $U_{1}^{b}$ to the estimation error of the distance between the vibrators and screen.

$K_{\varphi_{2}}^{a}$ is a voltage sensitivity coefficient of the source $a$ to the inaccuracy of the azimuth bearing to the source $b$;

$K_{e}$ is an ellipticity coefficient;

$K_{m}^{e}$ is a sensitivity of the ellipticity coefficient to the errors of the value $m$;

$K_{\gamma}^{e}$ is a sensitivity of the ellipticity coefficient to the errors of the angle $\gamma$;

$K_{\psi}^{e}$ is a sensitivity of the ellipticity coefficient to the errors of the angle $\psi$.

$K_{5}^{9}$ is a sensitivity factor of the voltage $U_{9}$ to instrumental error of the voltage $\dot{U}_{5}$;

$K_{8}^{9}$ is a sensitivity factor of the voltage $U_{9}$ to the error of the voltage $\dot{U}_{8}$;

$K_{5}^{11}$ is a sensitivity factor of the voltage $U_{11}$ to the error of the voltage $\dot{U}_{5}$;

$K_{8}^{11}$ is a sensitivity factor of the voltage $U_{11}$ to the error of the voltage $\dot{U}_{8}$.

$K_{9}^{\psi}$ is a sensitivity to change of the voltage $U_{9}$;

$K_{11}^{\psi}$ is a sensitivity to change of the voltage $U_{11}$;

$K_{\chi}^{E}$ is a sensitivity of the calculation result to the azimuthal angle error;

$K_{d}^{E}$ is a sensitivity of the calculated value of the field intensity to the errors in the distances between the elements of the antenna array;

$K_{d_{s c}}^{E}$ is a sensitivity of the calculated value of the field intensity to the errors in the distances from the vibrator to the screen.

$l$ is a length of the vibrator arm;

$l_{\text {eff }}$ is an effective length of the vibrators;

$m$ is a ratio of the meridional component of the field intensity to the azimuthal value;

$\mathbf{p}(\theta, \varphi)$ is an unit polarisation vector;

$T_{1}$ is a transmission coefficient of the measuring transducer;

$t_{a d}$ is a transmission coefficients of adders;

$t_{d}$ is a transmission voltage coefficient of detectors; $t_{f}$ is a transmission coefficients of a filter;

$T_{i N}$ is a circuit transmission coefficient;

$t_{r}$ is a transmission coefficients of a rectifier;

$t_{s q}$ is a transmission coefficients of a squarer;

$\dot{U}$ is a complex voltage;

$U_{\text {th }}$ is a particular threshold value;

$w_{p}$ is a function that takes a value $w_{p}=0$ if $p=5,8,9,11$ and $w_{p}=1$ if $p=1,2,3,4,6,7,10,12$;

$\alpha_{c}^{a}$ is a derivative of the phase $\alpha_{s}^{a} ;$

$\alpha_{s}^{a}$ is a phase shift, which occurs when the waves fall from the source $a$ to the antenna aperture;

$\alpha_{s}^{b}$ is a phase shift that occurs when the waves fall from the source $b$;

$\gamma_{s c}^{a}$ is a phase shift, which occurs due to mirror images of vibrators, for wave source $a$;

$\gamma_{s c}^{b}$ is a phase shift of the waves source $b$, which is caused by the screen;

$\gamma_{s}^{a}$ is a derivative of the phase $\gamma_{s c}^{a}$ with respect to the azimuthal angle;

$\gamma_{s}^{b}$ is a derivative of the phase $\gamma_{s c}^{b}$ with respect to the meridional angle;

$\delta a, \delta l_{\text {eff }}, \delta K$ are the relative errors of the amplification factor $a$, of the effective length $l_{\text {eff }}$ and the feeder transmission coefficient $K$;

$\Delta \theta_{a}$ is a determination error of the angle $\theta_{a} ;$

$\Delta \varphi$ is an error of the azimuthal angle;

$\Delta \theta$ is an error of the meridional angle;

$\theta$ is a meridional angle of the spherical coordinate system;

$\theta_{0}, \varphi_{0}$ are unit vectors of the spherical coordinate system;

$\lambda$ is a length of the electromagnetic wave;

$\sigma E_{a}^{\theta}, \sigma E_{a}^{\varphi}$ are mean square errors of the estimates of the field intensity components;

$\sigma T_{2}$ is an errors in transmissions of detectors and adders of the LC block of the 2nd level;

$\sigma T_{1}$ is a relative RMS error of the transmission coefficient $T_{1}$;

$\sigma \psi_{2}^{b}$ is a RMS error of function $\psi_{2}^{b}$;

$\varphi$ is an azimuth angle of the spherical coordinate system;

$\chi$ is an angular separation of radiation sources;

$\psi_{p}^{a}, \psi_{p}^{b}$ are products of harmonic quantities. 


\section{INTRODUCTION}

Radiomonitoring antenna arrays are used not only as a means of monitoring the electromagnetic environment but also as measuring devices for onboard and ground equipment. The antenna array makes it possible to determine the angular coordinates of the radiation sources, the polarization characteristics of the electromagnetic waves, to estimate the intensity of the electromagnetic fields and others.

In this regard, there is a need to provide a radiomonitoring antenna with metrological characteristics as part of the measuring device. Such features can be obtained as a result of experimental research of the finished product.

However, the possibility to provide an accuracy requirement of the device is lost, or its level is ascertained. It is quite challenging to improve it practically. From the other hand, some analytical expressions show the influence of different elements and circuits of the device on the accuracy of measurements of radiation field parameters. In this case, the measurement errors can be reduced to the required level by choice of specific components.

The object of study is the process of constructing the antenna systems with signal processing for radio monitoring stations.

The subject of study is the process of constructing the antenna systems with signal processing for radio monitoring stations.

The purpose of the work is to build a mathematical model of the antenna system with the characteristics of accuracy, which took into account the real transmission coefficients of the most critical structural components.

\section{PROBLEM STATEMENT}

Since the antenna monitoring system is primarily a measuring device, there is a need to provide the system with accuracy characteristics. Methodical and instrumental errors are the most critical characteristics of the measuring devices. It means that dependence of these errors on the parameters of the structural elements of a signal processing device is integrated with the antenna array. Therefore, it is necessary to construct a mathematical model of the antenna system, which would take into account the real transfer coefficients of the most critical structural components. Besides, to ensure transparent functional expressions between voltages in a mathematical model, the number of variable informative voltages should be limited. With this approach, the definition of instrumental errors is significantly simplified. Analytical expressions become more suitable for evaluating the influence of structural elements on the accuracy of measurement processes.

\section{REVIEW OF THE LITERATURE}

As known, an increase in the number of radioelectronic means leads to a complication of the electromagnetic environment and, accordingly, requires a solution to the problem of ensuring electromagnetic compatibility (EMC) $[1,2]$. In other words, there is a need for the use of measuring means of radiomonitoring [3-5], which in their composition have an antenna system. In radiomonitoring systems, antennas of various configurations are used - from the simple vibrator [6] to complex antenna arrays $[7,8]$.

In the article [9] an ultra-wideband monopole antenna for EMC measurements is presented. The proposed EMC measuring antenna can be used for EMC radiations detection in printed circuit boards (PCB) and many digital devices such as mobile handsets, PDAs and other mobile communication systems. An article [10] presents two new types of ultra-wideband antennas for EMC measurements. Both antennas have a compact size and can have multiple ports for flexibility in measurement tests. The radiation patterns of the antennas can be directional or of multibeam. The antennas have a low manufacture cost and lightweight, easy for installation, which is especially crucial for lowfrequency antennas. The designed tapered TEM horn antenna [11] has the merits such as wideband, simple feeding network, low profile compact size with reasonably good antenna performances such as return loss, peak gain and radiation patterns. A paper [12] presents a new biconical broadband antenna, which is used for EMC test application. Compared with the conventional biconical antenna, the proposed antenna is small in size and good in electrical characteristics.

Smart antenna arrays provide more opportunities for monitoring the electromagnetic field. The adaptive beamforming algorithm can aim at the direction-ofarrival of jammer automatically. In an article [13], a new robust beamforming control method is presented to widen nulls of an adaptive antenna array. In this proposed method, the weight vector is optimized to involve the minimization of a quadratic function. The presented method can provide improved robustness against the interference angle shaking and suppress the interference signals. In a letter [14], the performance of smart antennas with uniform circular arrays (UCAs) is examined. The primary motivation for this selection is the symmetry UCAs possess. That provides UCAs with a significant advantage. It lies in the fact that the beam azimuthally through 360 with little change in the beamwidth or the sidelobe level can be scanned. A paper [15] describes an approach to interference suppression by adaptively thinning the array to reject sidelobe interference. Changing the random thinning can lower a sidelobe or place a null in the direction of interference. In a paper [16], a novel symmetric weighted thinned array with pattern reconfigurable antenna is proposed to achieve wide-angle scanning performance.

Designs of four-element antenna systems with signal processing have been developed for measuring the parameters of the electromagnetic field [17]. An example of calculating the metrological characteristics of this antenna system was also presented, as well as possible measurement errors and their main sources [18]. It should be noted that the measurement errors of the output values 
were presented as the sum of the components with specific influence coefficients. They did not include the transmission coefficients of real elements of the structural diagram.

\section{MATERIALS AND METHODS}

To study the accuracy characteristics of radiomonitoring antenna systems a four-element antenna system was selected (Fig. 1) [19, 20]. The operation mode of the antenna system is given by the processor and switches Sw1-Sw4. The main mode is where the switch outputs are connected to the terminals of the antenna unit 1', 1", 2 ' and 2". The signal processing device consists of the following parts: an electromechanical rotary device (EMRD), switches Sw1-Sw4, test voltage generator (TVG), controlled oscillator unit (COU), switch control unit (SCU), amplification and frequency transformation unit (AFTU), amplitude-phase correctors (AFC), subtractor $\Delta 1-\Delta 4$, adders $\Sigma 1-\Sigma 4$, amplitude detectors D1-D8, squarers Q1 and Q2, filters F1 and F2, rectifiers R1 and $\mathrm{R} 2$, the device of display and recording signals (DDRS), the identification device (ID).
The block diagram in Fig. 1 can be divided into two main parts - an antenna array and a block of amplification and frequency conversion of signals.

The latter consists of the following parts:

- a measuring transducer (MT) creates voltages that are proportional to the components of the electric field intensity in a linear orthogonal polarization basis;

- double-level linear converter (LC) is based on linear adders and consists of a block of the 1st level (1 LC) and a block of the 2nd level (2 LC);

- block of nonlinear transformations (BNT);

- signal identification device (SID);

- processor and device for indication and registration of signals (DIRS).

The combination of these blocks and the functional connections between them are shown in Fig. 2.

A new (simpler) voltage numbering was introduced for the convenience of further analysis of the block diagram. The transition from the voltages indicated in the structural diagram $[19,20]$ to the voltages used in the block diagram is given in Table 1.

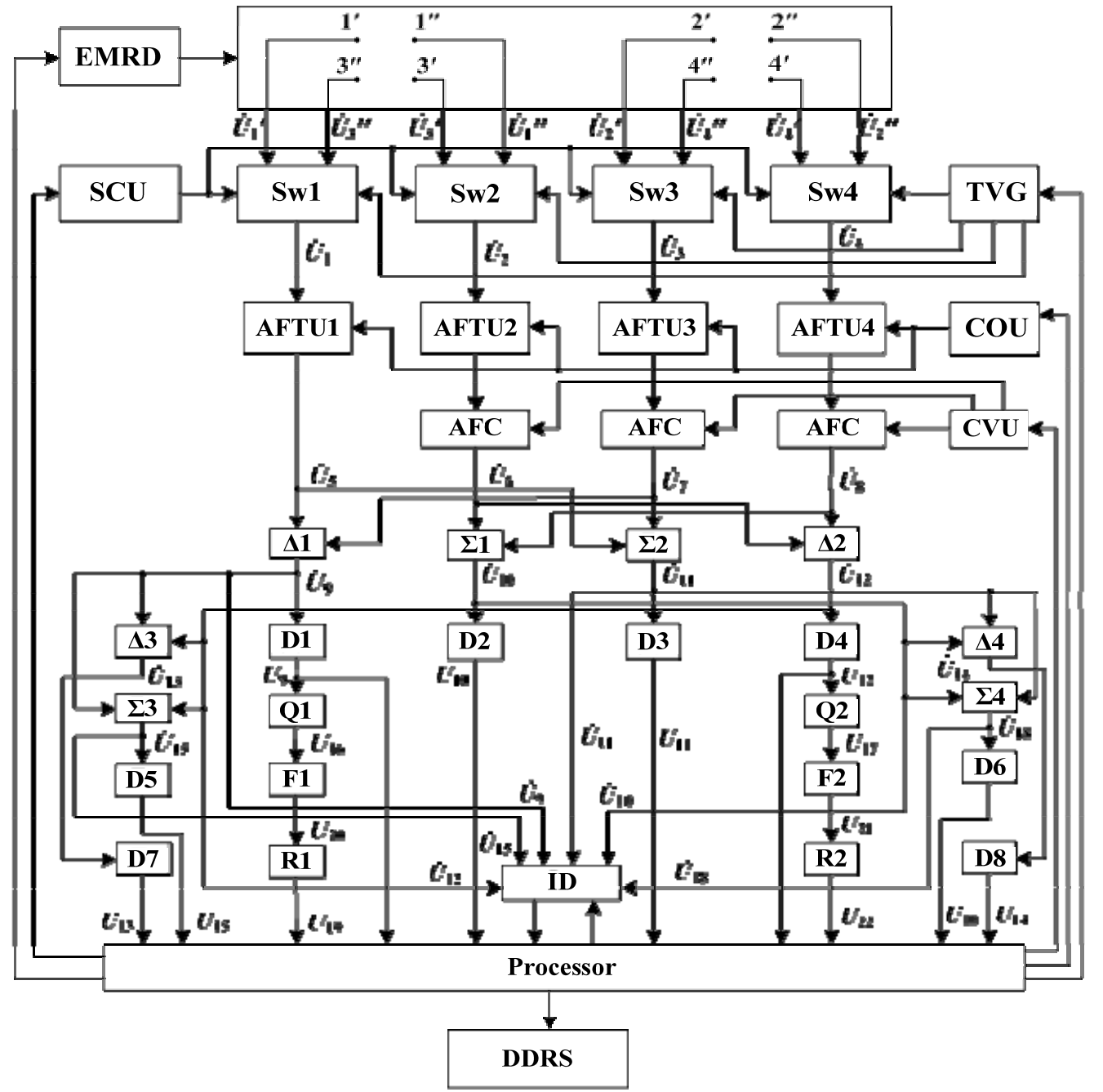

Figure 1 - Structural diagram of the antenna system $[19,20]$ 
Table 1 - The equivalence of the voltages of the structural diagram $[19,20]$ and the block diagram is shown in Fig. 2

\begin{tabular}{|c|c|c|c|c|c|c|c|c|c|c|c|c|c|c|}
\hline $\begin{array}{c}\text { Structural } \\
\text { diagram }\end{array}$ & $\dot{U}_{5}$ & $\dot{U}_{6}$ & $\dot{U}_{7}$ & $\dot{U}_{8}$ & $\dot{U}_{9}$ & $\dot{U}_{10}$ & $\dot{U}_{11}$ & $\dot{U}_{12}$ & $\dot{U}_{13}$ & $\dot{U}_{14}$ & $\dot{U}_{15}$ & $\dot{U}_{18}$ & $\dot{U}_{19}$ & $\dot{U}_{22}$ \\
\hline $\begin{array}{c}\text { Block } \\
\text { diagram }\end{array}$ & $\dot{U}_{1}$ & $\dot{U}_{2}$ & $\dot{U}_{3}$ & $\dot{U}_{4}$ & $\dot{U}_{5}$ & $\dot{U}_{6}$ & $\dot{U}_{7}$ & $\dot{U}_{8}$ & $\dot{U}_{9}$ & $\dot{U}_{10}$ & $\dot{U}_{11}$ & $\dot{U}_{12}$ & $\dot{U}_{13}$ & $\dot{U}_{14}$ \\
\hline
\end{tabular}

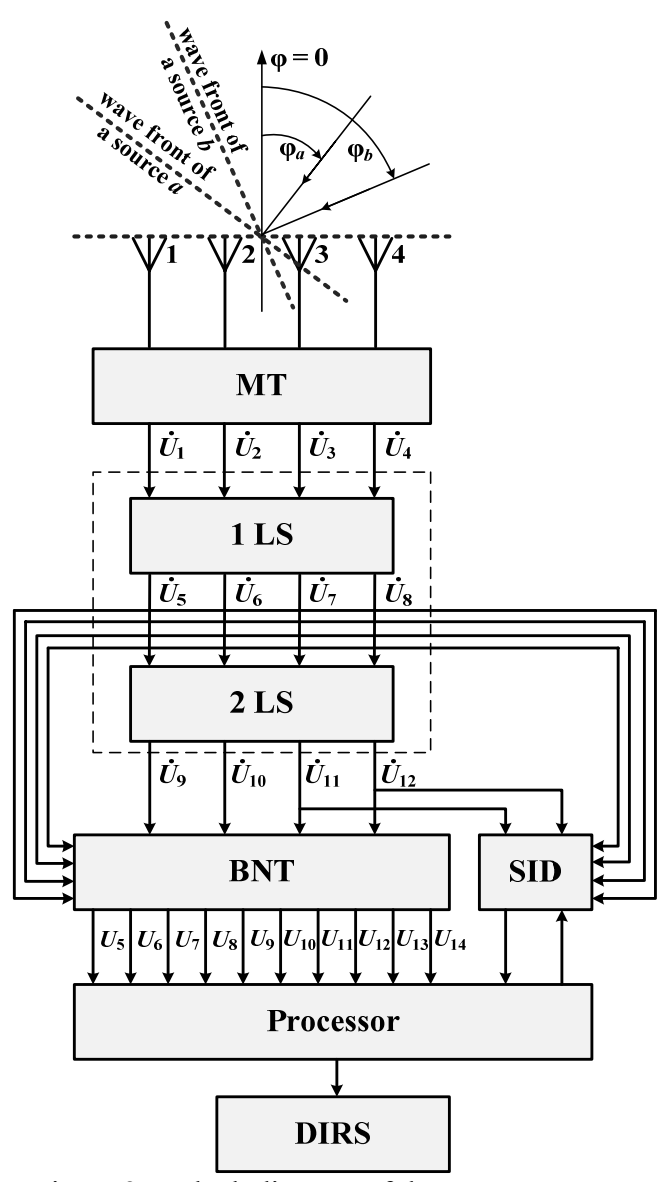

Figure 2 - Block diagram of the antenna system

The antenna unit consists of four elements located on the tops of an imaginary quadrilateral [19]. Each antenna element consists of two mutually perpendicular vibrators (symmetrical or non-symmetrical). Vibrators axes coincide either with the perpendicular to the surface of the earth or with the horizon line. So, the vertical vibrator has the directivity characteristic:

$$
F(\theta)=\sin \theta,
$$

and the unit polarization vector [7] takes the form $\mathbf{p}_{v}(\theta, \varphi)=\theta_{\mathbf{0}}$, where $\theta$ is the meridional angle of the spherical coordinate system; $\varphi$ is the azimuth angle; $\theta_{0}$ is a unit vector of the spherical coordinate system.

The directivity characteristic of a horizontal vibrator is defined as:

$$
F(\theta, \varphi)=\sqrt{1-\sin ^{2} \theta \sin ^{2} \varphi},
$$

and the unit polarization vector is $\mathbf{p}_{h}(\theta, \varphi)=\varphi_{\mathbf{0}}$, where $\varphi_{0}$ is a unit vector of the spherical coordinate system, in which the angle $\varphi$ is measured from the normal to the antenna aperture.

Expressions (1) and (2) are valid when $l<<\lambda$, where $l$ is the length of the vibrator arm, and $\lambda$ is the length of the electromagnetic wave. This condition is satisfied when using active antennas. Therefore, formulas (1) and (2) are characterising the properties of active antennas with high accuracy.

The antenna array through the line switch in the transmitter operates in three configurations, which provide the ability to work in three modes. In the first, basic mode (mode $A$ ) the antenna array consists of two elements - two vertical and two horizontal vibrators. The phase centers of the vibrators are horizontally separated by a distance $d$ (the square side length). In mode $B$, four vertical vibrators are used, which are located on the square tops. There is a distance $d$ between their phase centers. In mode $C$, the same antenna array is created as in mode $B$, but with horizontal vibrators.

The set of vibrators are located at a distance $d_{s c}$ from the screen. This is a reason that in any mode, in the analytical expression for the output voltage of the vibrator the multiplier $i 2 \sin \left(k d_{s c} \sin \theta \cos \varphi\right)$ appears, where $k=2 \pi / \lambda$ is the wave number.

The following matrix equation determines the dependence of the output voltages from the intensities of the electric fields in mode A:

$$
\begin{gathered}
{\left[\begin{array}{c}
\dot{U}_{1} \\
\dot{U}_{2} \\
\dot{U}_{3} \\
\dot{U}_{4}
\end{array}\right]=i T_{1}\left[\begin{array}{cc}
\theta_{\mathbf{0}} F\left(\theta_{a}\right) e^{i \alpha_{s}^{a}} & \theta_{\mathbf{0}} F\left(\theta_{b}\right) e^{i \alpha_{s}^{b}} \\
\varphi_{\mathbf{0}} F\left(\theta_{a}, \varphi_{a}\right) e^{i \alpha_{s}^{a}} & \varphi_{\mathbf{0}} F\left(\theta_{b}, \varphi_{b}\right) e^{i \alpha_{s}^{b}} \\
\theta_{\mathbf{0}} F\left(\theta_{a}\right) e^{-i \alpha_{s}^{a}} & \theta_{\mathbf{0}} F\left(\theta_{b}\right) e^{-i \alpha_{s}^{b}} \\
\varphi_{\mathbf{0}} F\left(\theta_{a}, \varphi_{a}\right) e^{-i \alpha_{s}^{a}} & \varphi_{\mathbf{0}} F\left(\theta_{b}, \varphi_{b}\right) e^{-i \alpha_{s}^{b}}
\end{array}\right] \times} \\
\times\left[\begin{array}{l}
\mathbf{E}_{a} \sin \gamma_{s c}^{a} \\
\mathbf{E}_{b} \sin \gamma_{s c}^{b}
\end{array}\right],
\end{gathered}
$$

where $\alpha_{s}^{a}=k_{a} d \sin \theta_{a} \sin \varphi_{a}$ is a phase shift, which occurs when the waves fall from the source $a$ to the antenna aperture (Fig. 2); $\alpha_{s}^{b}=k_{b} d \sin \theta_{b} \sin \varphi_{b}$ is a phase shift that occurs when the waves fall from the source $b ; \quad \gamma_{s c}^{a}=k_{a} d_{s c} \sin \theta_{a} \cos \varphi_{a}$ is a phase shift, which occurs due to mirror images of vibrators, for wave source $a ; \gamma_{s c}^{b}=k_{b} d_{s c} \sin \theta_{b} \cos \varphi_{b}$ is a phase shift 
of the waves source $b$, which is caused by the screen; $k_{a}=2 \pi / \lambda_{a}, k_{b}=2 \pi / \lambda_{b}$ are wave numbers for the waves of sources $a$ and $b ; \mathbf{E}_{a}, \mathbf{E}_{b}$ are vectors of field intensities from sources $a$ and $b ; T_{1}=2 a l_{\text {eff }} K$ is a transmission coefficient of the measuring transducer; $a$ is a transmission coefficient of frequency converters and amplifiers of intermediate frequency; $l_{\text {eff }}$ is the effective length of the vibrators; $K$ is a transmission coefficient from vibrator terminals to the input terminals of frequency converters.

Equation (3) takes into account that electromagnetic waves, which are emitted by two independent sources at almost the same frequencies with wavelengths $\lambda_{a}$ and $\lambda_{b}$, act on the radiomonitoring antenna.

The transmission coefficients $t_{a d}$ of the adders should be taking into account. Then received signals with voltages $\dot{U}_{1}, \ldots, \dot{U}_{4}$, are transformed into the first level following the equation:

$$
\left[\begin{array}{c}
\dot{U}_{5} \\
\dot{U}_{6} \\
\dot{U}_{7} \\
\dot{U}_{8}
\end{array}\right]=\left[\begin{array}{cccc}
t_{a d} & 0 & -t_{a d} & 0 \\
0 & t_{a d} & 0 & t_{a d} \\
t_{a d} & 0 & t_{a d} & 0 \\
0 & t_{a d} & 0 & -t_{a d}
\end{array}\right] \times\left[\begin{array}{c}
\dot{U}_{1} \\
\dot{U}_{2} \\
\dot{U}_{3} \\
\dot{U}_{4}
\end{array}\right] .
$$

The absolute nominal values of the transmission coefficients $t_{a d}$ of adders are the same. However, when considering instrumental errors, the value cannot be regarded as a common factor. It cannot be taken out of the limits of the transfer matrix. The transmission coefficients $t_{a d}$ for each voltage are set independently. Therefore, the errors of any element of the transmission matrix must be taken into account without regard to different transmission coefficients.

Signals with voltages obtained by the second level of linear transformations:

$$
\left[\begin{array}{l}
\dot{U}_{9} \\
\dot{U}_{10} \\
\dot{U}_{11} \\
\dot{U}_{12}
\end{array}\right]=\left[\begin{array}{cccc}
t_{a d} & 0 & 0 & -t_{a d} \\
0 & -t_{a d} & t_{a d} & 0 \\
t_{a d} & 0 & 0 & t_{a d} \\
0 & t_{a d} & t_{a d} & 0
\end{array}\right] \times\left[\begin{array}{c}
\dot{U}_{5} \\
\dot{U}_{6} \\
\dot{U}_{7} \\
\dot{U}_{8}
\end{array}\right] .
$$

The block of nonlinear transformations (BNT) incorporates 12 amplitude detectors, which form direct voltages proportional to the amplitudes of the corresponding alternating voltages. As the result, at the outputs of the BNT the voltages are obtained:

$$
U_{s}=t_{d}\left|\dot{U}_{3}\right|, s=5,6, \ldots, 12,
$$

where $t_{d}$ is the transmission voltage coefficient of the detectors.
Voltages $\dot{U}_{5}$ and $\dot{U}_{8}$ are used in the block of nonlinear transformation. Based on this, for determination of angles $\varphi_{a}$ and $\varphi_{b}$ indicator signals $\dot{U}_{13}$ and $\dot{U}_{14}$ are created.

More simplified notation for some quantities should be introduced before writing expressions for indicator voltages of the azimuthal angles of radiation sources. It is advisable to present it in the form the voltages, which are used in equations (3), (4), and (5):

$$
\dot{U}_{p}=\left(\dot{U}_{p}^{a} \psi_{p}^{a}+\dot{U}_{p}^{b} \psi_{p}^{b}\right) e^{i w_{p} \frac{\pi}{2}}
$$

where $\dot{U}_{p}^{a}$ and $\dot{U}_{p}^{b}$ are amplitude factors that depend on field intensities $\vec{E}_{a}, \vec{E}_{b}$ and index $p ; \psi_{p}^{a}$ and $\psi_{p}^{b}$ are products of harmonic quantities; $w_{p}$ is a function that takes a value $w_{p}=0$ if $p=5,8,9,11$ and $w_{p}=1$ if $p=1,2,3,4,6,7,10,12$.

The quantities that are used in equation (3) are written for the static mode. That is for the antenna system state, when the normal to the aperture of the antenna array coincides with the angles $\theta=90^{\circ}$ and $\varphi=0$. Or they coincides with the direction to one of the radiation sources.

In the case of direction-finding, the aperture of the antenna rotates in the meridional and azimuthal planes. Therefore the phase shifts acquire the following values:

$$
\left.\begin{array}{l}
\alpha_{s}^{a}=k_{a} d \cos \left(\theta_{a}-\theta\right) \sin \left(\varphi_{a}-\varphi\right) ; \\
\alpha_{s}^{b}=k_{b} d \cos \left(\theta_{b}-\theta\right) \sin \left(\varphi_{b}-\varphi\right) ; \\
\gamma_{s c}^{a}=k_{a} d_{s c} \cos \left(\theta_{a}-\theta\right) \cos \left(\varphi_{a}-\varphi\right) ; \\
\gamma_{s c}^{b}=k_{b} d_{s c} \cos \left(\theta_{b}-\theta\right) \cos \left(\varphi_{b}-\varphi\right),
\end{array}\right\},
$$

where $\theta, \varphi$ are the angular direction of the normal to the aperture of the antenna array, that is, the angles $\theta$ and $\varphi$ are the deviation of the antenna from a given initial state.

Formulas for the directivity characteristics (1) and (2) are converted in the same way:

$$
\begin{gathered}
F\left(\theta_{q}\right)=\cos \left(\theta_{q}-\theta\right), \quad q=a, b \\
F\left(\theta_{q}, \varphi_{q}\right)=\sqrt{1-\cos ^{2}\left(\theta_{q}-\theta\right) \sin ^{2}\left(\varphi_{q}-\varphi\right)} .
\end{gathered}
$$

In the exponential indexes, the minus sign refers to other indexes of functions $\psi$, that is, to $p=3,4$. The expressions for the amplitude factors $\dot{U}^{a}$ and $\dot{U}^{b}$ change depending on the index $p$. Thus, to $p=\overline{1,4}$ have the following voltage values 


$$
\left[\begin{array}{c}
\dot{U}_{1} \\
\dot{U}_{2} \\
\dot{U}_{3} \\
\dot{U}_{4}
\end{array}\right]=i\left[\begin{array}{cccc}
\psi_{1}^{a} & \psi_{1}^{b} & 0 & 0 \\
0 & 0 & \psi_{2}^{a} & \psi_{2}^{b} \\
\psi_{3}^{a} & \psi_{3}^{b} & 0 & 0 \\
0 & 0 & \psi_{4}^{a} & \psi_{4}^{b}
\end{array}\right] \times\left[\begin{array}{c}
\dot{U}_{a}^{\theta} \\
\dot{U}_{b}^{\theta} \\
\dot{U}_{a}^{\varphi} \\
\dot{U}_{b}^{\varphi}
\end{array}\right],
$$

where functions $\psi_{p}^{q}$ are defined as

$$
\left.\begin{array}{c}
\psi_{1,3}^{q}=e^{ \pm i \alpha_{s}^{q}} \cos \left(\theta_{q}-\theta\right) \sin \gamma_{s c}^{q}, \text { if } q=a, b ; \\
\psi_{2,4}^{q}=e^{ \pm i \alpha_{s}^{q}} \sqrt{1-\cos ^{2}\left(\theta_{q}-\theta\right) \sin ^{2}\left(\varphi_{q}-\varphi\right)} \sin \gamma_{s c}^{q} .
\end{array}\right\}
$$

The voltages that are included in the right column matrix equation (8) are such values

$$
\left.\begin{array}{l}
\dot{U}_{q}^{\theta}=T_{1} E_{q}^{\theta} ; \\
\dot{U}_{q}^{\varphi}=T_{1} E_{q}^{\varphi}, q=a, b,
\end{array}\right\}
$$

where $T_{1}=2 a l_{e f f} K$ and $\dot{E}_{q}^{\theta}=\left(\theta_{\mathbf{0}}, \dot{\mathbf{E}}_{\mathbf{q}}\right), \dot{E}_{q}^{\varphi}=\left(\varphi_{\mathbf{0}}, \dot{\mathbf{E}}_{\mathbf{q}}\right)$.

The expression for the voltages $U_{13}$ and $U_{14}$ can be written in the form using this notation:

$$
\left.\begin{array}{l}
U_{13}=T_{i N} U_{a}^{\theta} U_{b}^{\theta} \psi_{5}^{a} \psi_{5}^{b} ; \\
U_{14}=T_{i N} U_{a}^{\varphi} U_{b}^{\varphi} \psi_{8}^{a} \psi_{8}^{b},
\end{array}\right\}
$$

where $T_{i N}=4 t_{a d} t_{d} t_{r} t_{s q} t_{f}$ is the circuit transmission coefficient, which consists of an adder with a transmission $t_{a d}$, a detector with a transmission $t_{d}$, a rectifier with a transmission $t_{r}$, a squarer with a transmission $t_{s q}$ and a filter with a transmission $t_{f}$;

$$
\begin{gathered}
\psi_{5}^{q}=\cos \left(\theta_{q}-\theta\right) \sin \alpha_{s}^{q} \sin \gamma_{s c}^{q}, \\
\psi_{8}^{q}=\sqrt{1-\cos ^{2}\left(\theta_{q}-\theta\right) \sin ^{2}\left(\varphi_{q}-\varphi\right)} \sin \alpha_{s}^{q} \sin \gamma_{s c}^{q}, \\
q=a, b .
\end{gathered}
$$

From expressions (10) it follows that the voltages $U_{13}$ and $U_{14}$ acquire a zero value at $\varphi_{a}=\varphi$ and $\varphi_{b}=\varphi$. That is, the antenna aperture must be rotated in a horizontal plane until the indicator voltages $U_{13}$ and $U_{14}$ are zero. Thus, the azimuthal directions of the sources $a$ and $b$ are located.

To estimate the error in determining azimuth, consider the case where the angle $\varphi$ is close to the angle $\varphi_{b}$. Antenna position setting is completed when the voltages $U_{13}$ and $U_{14}$ nearer to a particular threshold value $U_{t h}$.
Considering that $\varphi_{b}-\varphi=\Delta \varphi$, from expressions (11) with $\Delta \varphi_{b}<<1$ the following expressions can be obtained:

$$
\begin{aligned}
& \sin \left[k_{b} d \cos \left(\theta_{b}-\theta\right) \sin \Delta \varphi_{b}\right] \leq M_{\theta}^{b} ; \\
& \sin \left[k_{b} d \cos \left(\theta_{b}-\theta\right) \sin \Delta \varphi_{b}\right] \leq M_{\varphi}^{b},
\end{aligned}
$$

where the right-hand side of the equations (12) the values $M_{\theta}^{b}$ and $M_{\varphi}^{b}$ represent the next functions

$M_{\theta}^{b}=U_{t h} /\left(\begin{array}{l}C_{\theta} \cos \left(\theta_{a}-\theta\right) \cos \left(\theta_{b}-\theta\right) \sin \left[k_{a} d \cos \left(\theta_{a}-\theta\right) \sin \chi\right] \times \\ \times \sin \left[k_{a} d_{s c} \cos \left(\theta_{a}-\theta\right) \cos \chi\right] \sin \left[k_{b} d_{s c} \cos \left(\theta_{b}-\theta\right)\right]\end{array}\right) ;$ $M_{\varphi}^{b}=U_{t h} /\left(\begin{array}{l}C_{\varphi} \sqrt{1-\cos ^{2}\left(\theta_{a}-\theta\right) \sin ^{2} \chi} \sin \left[k_{a} d \cos \left(\theta_{a}-\theta\right) \sin \chi\right] \times \\ \times \sin \left[k_{a} d_{s c} \cos \left(\theta_{a}-\theta\right) \cos \chi\right] \sin \left[k_{b} d_{s c} \cos \left(\theta_{b}-\theta\right)\right]\end{array}\right) ;$

$C_{\theta}=T_{i N} U_{a}^{\theta} U_{b}^{\theta}, \quad C_{\varphi}=T_{i N} U_{a}^{\varphi} U_{b}^{\varphi}$ are values that are independent of coordinate angles; $\chi=\varphi_{a}-\varphi_{b}$ is the angular separation of radiation sources. The value of the meridional angle $\theta$ in the functions $M_{\theta}^{q}$ and $M_{\varphi}^{q}$ is equal to $\pi / 2$.

From equations (12) it follows that

$$
\left.\begin{array}{c}
\Delta \varphi_{b}^{\prime} \leq \arcsin \left(\frac{\arcsin M_{\theta}^{b}}{k_{b} d \sin \theta_{b}}\right), \\
\text { or } \\
\Delta \varphi_{b}^{\prime \prime} \leq \arcsin \left(\frac{\arcsin M_{\varphi}^{b}}{k_{b} d \sin \theta_{b}}\right) .
\end{array}\right\}
$$

The azimuth error $\varphi_{a}$ is determined by the same formulas (13) when the index $b$ is changed to index $a$.

For estimation of the measurement error of the meridional angle $\theta_{a}$ it is necessary to consider the operation of the antenna system in mode $B$. Since the perpendicular to the aperture coincides with the azimuthal angle $\varphi_{b}$, the matrix equation (3) is somewhat simplified:

$$
\left[\begin{array}{c}
\dot{U}_{1} \\
\dot{U}_{2} \\
\dot{U}_{3} \\
\dot{U}_{4}
\end{array}\right]=i\left[\begin{array}{ccc}
e^{i \alpha_{s}^{a}} & e^{i \alpha_{z}^{a}} & e^{i \alpha_{z}^{b}} \\
e^{i \alpha_{s}^{a}} e^{-i \alpha_{z}^{a}} & e^{-i \alpha_{z}^{b}} \\
e^{-i \alpha_{s}^{a}} e_{z}^{i \alpha_{z}^{a}} & e^{i \alpha_{z}^{b}} \\
e^{-i \alpha_{s}^{a}} e^{-i \alpha_{z}^{a}} & e^{-i \alpha_{z}^{b}}
\end{array}\right] \times\left[\begin{array}{c}
\dot{U}_{a}^{\theta} \cos \left(\theta_{a}-\theta\right) \sin \gamma_{s c}^{a} \\
\dot{U}_{b}^{\theta} \cos \left(\theta_{b}-\theta\right) \sin \gamma_{s c}^{b}
\end{array}\right],
$$

where $\alpha_{s}^{a}=k_{a} d \cos \left(\theta_{a}-\theta\right) \sin \chi ; \alpha_{s}^{b}=0 ;$

$$
\begin{aligned}
\gamma_{s c}^{a} & =k_{a} d_{s c} \cos \left(\theta_{a}-\theta\right) \cos \chi ; \\
\gamma_{s c}^{b} & =k_{b} d_{s c} \cos \left(\theta_{b}-\theta\right) ;
\end{aligned}
$$




$$
\alpha_{z}^{q}=k_{q} d \sin \left(\theta_{q}-\theta\right) ; q=a, b .
$$

After the first level of linear transformations, two voltages are formed. They depending only on the field intensity of the source $a$. Their values according to equation (4) equal to

$$
\left.\begin{array}{l}
\dot{U}_{5}=2 \dot{U}_{a}^{\theta} \sin \alpha_{s}^{a} \cos \left(\theta_{a}-\theta\right) \sin \gamma_{s c}^{a} e^{i \alpha_{z}} \\
\dot{U}_{8}=2 \dot{U}_{a}^{\theta} \sin \alpha_{s}^{a} \cos \left(\theta_{a}-\theta\right) \sin \gamma_{s c}^{a} e^{-i \alpha_{z}}
\end{array}\right\}
$$

At the second level of linear transformations of these voltages, two more voltages are formed:

$$
\left.\begin{array}{l}
\dot{U}_{9}=i 4 \dot{U}_{a}^{\theta} \cos \left(\theta_{a}-\theta\right) \sin \alpha_{s}^{a} \sin \gamma_{s c}^{a} \sin \alpha_{z} \\
\dot{U}_{11}=4 \dot{U}_{a}^{\theta} \cos \left(\theta_{a}-\theta\right) \sin \alpha_{s}^{a} \sin \gamma_{s c}^{a} \cos \alpha_{z} .
\end{array}\right\}
$$

By rotating the aperture of the antenna array in the meridional plane, it was achieved that the value $\dot{U}_{9}$ is less than the threshold value $U_{t h}>\dot{U}_{9}$. Which can be interpreted as the orientation of the normal antenna aperture to the direction of wave radiation from the source $a$. When this voltage $\dot{U}_{11}$ takes on the value

$$
\dot{U}_{11}=4 \dot{U}_{a}^{\theta} \sin \left(k_{a} d \sin \chi\right) \sin \left(k_{a} d_{s c} \cos \chi\right) .
$$

The determination error of the angle $\theta_{a}$ depends on the threshold voltage level $U_{t h}$, and if $U_{9} \approx 0$ is equal to

$$
\Delta \theta_{a} \leq \arcsin \left(\frac{1}{k_{a} d} \arcsin B_{\theta}^{a}\right)
$$

where $B_{\theta}^{a}=\frac{U_{t h}}{4 U_{a}^{\theta} \sin \left(k_{a} d \sin \chi\right) \sin \left(k_{a} d_{s c} \cos \chi\right)}$.

The amplitude value of the voltage $U_{11}$ (15) makes it possible to calculate the meridional component of the intensity field vector of the radiation source $a$. Using the relation (10), it follows

$$
E_{a}^{\theta}=\frac{U_{11}}{4 t_{d} t_{a d}^{2} T_{1} \sin \left(k_{a} d \sin \chi\right) \sin \left(k_{a} d_{s c} \cos \chi\right)} .
$$

In the case when the horizontal component $E_{a}^{\varphi}$ more than the vertical component $E_{a}^{\theta}$, the meridional angular coordinate of the source $a$ is better to determine in the mode $C$ of operation of the antenna system. In this mode, the antenna array, as noted earlier, consists of four horizontal vibrators. The matrix equation (14) (C) Shcherbyna O. A., Ilnitskyi L. Ya., Mykhalchuk I. I., Kozhokhina O. V., 2020 DOI 10.15588/1607-3274-2020-3-4 varies only at the expense of multipliers in the right matrix column, which are the direction characteristics of the individual vibrator, namely: $U_{a}^{\theta} \cos \left(\theta_{a}-\theta\right)$ changes to $U_{a}^{\varphi} \sqrt{1-\cos ^{2}\left(\theta_{a}-\theta\right) \sin ^{2} \chi}$, and $U_{b}^{\theta} \cos \left(\theta_{b}-\theta\right)$ to $U_{b}^{\varphi}$.

As a result of such a simple transformation of equation (14), it can be written that

$$
\Delta \theta_{a} \leq \arcsin \left(k_{a} \arcsin B_{\varphi}^{a}\right),
$$

where $B_{\varphi}^{a}=\frac{U_{t h}}{4 \dot{U}_{a}^{\varphi} \cos \chi \sin \left(k_{a} d \sin \chi\right) \sin \left(k_{a} d_{s c} \cos \chi\right)}$.

The azimuthal component of the field intensity vector equal

$$
E_{a}^{\varphi}=\frac{U_{11}}{4 t_{d} t_{a d}^{2} T_{1} \cos \chi \sin \left(k_{a} d \sin \chi\right) \sin \left(k_{a} d_{s c} \cos \chi\right)} .
$$

After determining the angular coordinates of the radiation sources, the antenna system returns to the main mode of operation - mode $A$.

Assume that the radiation of the source $b$ is suppressed. In this case, the polar axis of the spherical coordinate system is parallel to the axes of the vertical vibrators when $\theta_{a}=90^{\circ}$. The direction to the radiation source $b$ coincides with the perpendicular to the antenna aperture, that is $\varphi_{b}=0^{\circ}$.

Denote the angular separation of radiation sources in the azimuthal plane as $\chi=\varphi_{a}-\varphi_{b}$, and in the meridional plane as $\chi_{\theta}=\theta_{a}-\theta_{b}$. The phase shifts, what occurs due to the difference in beams paths, acquire the following values:

$$
\left.\begin{array}{c}
\alpha_{s}^{a}=k_{a} d \sin \chi \\
\alpha_{s}^{b}+\Delta \alpha_{s}^{b}=0 \pm\left(k_{b} d \cos \chi_{\theta}\right) \Delta \varphi \\
\gamma_{s c}^{a}=k_{a} d_{s c} \cos \chi \\
\gamma_{s c}^{b}=k_{b} d_{s c} \cos \chi_{\theta} .
\end{array}\right\}
$$

Taking into account the phase shifts values and the fact that $\alpha_{s}^{a}<<1$ from formula (9) expressions for the functions $\psi_{p}^{q}$ is obtained

$$
\left.\begin{array}{c}
\psi_{1,3}^{a}=e^{ \pm i \alpha_{s}^{a}} \sin \gamma_{s c}^{a} ; \\
\psi_{1,3}^{b}+\Delta \psi_{1,3}^{b}=\left(1 \pm i \Delta \varphi k_{b} d \cos \chi_{\theta}\right) \cos \chi_{\theta} \sin \gamma_{s c}^{b} ; \\
\psi_{2,4}^{a}=e^{ \pm i \alpha_{s}^{a}} \cos \chi \sin \gamma_{s c}^{a} ; \\
\psi_{2,4}^{b}=\left(1 \pm i \Delta \varphi k_{b} d \cos \chi_{\theta}\right) \sin \gamma_{s c}^{b} .
\end{array}\right\}
$$


Voltages $U_{p}$ (when $p=\overline{1,4}$ ), using expressions (18) and (19), are written in the form (7). That make it possible to obtain a ratio for calculating instrumental errors. It is necessary to bear in mind the fact that the individual components of the total error $\Delta U_{p}$ differ both in amplitude and phase. Therefore, the correct error estimate is the root-mean-square (RMS) value. It should also be noted that the RMS errors of voltages $U_{1}$ and $U_{3}, U_{2}$ and $U_{4}$ are the same, that is $\sigma U_{3}=\sigma U_{1}$ and $\sigma U_{4}=\sigma U_{2}$

A voltage error $U_{1}$ can be obtained, taking into account all the above

$$
\begin{aligned}
& \sigma U_{1}=U_{a}^{\theta} \theta\left\{\left(\sigma T_{1}\right)^{2} \sin ^{2} \gamma_{s c}^{a}+\left(\sigma \psi_{1}^{a}\right)^{2}\right\}^{\frac{1}{2}}+ \\
& +U_{b}^{\theta}\left\{\left(\sigma T_{1}\right)^{2} \cos ^{2} \chi_{\theta} \sin ^{2} \gamma_{s c}^{b}+\left(\sigma \psi_{1}^{b}\right)^{2}\right\}^{\frac{1}{2}},
\end{aligned}
$$

where the content of the component of the error $\sigma U_{1}$ is defined as $\sigma T_{1}=\sqrt{(\delta a)^{2}+\left(\delta l_{\text {eff }}\right)^{2}+(\delta K)^{2}}$ is the relative RMS error of the transmission coefficient $T_{1}$; $\delta a, \delta l_{\text {eff }}, \delta K$ are the relative errors of the amplification factor $a$, of the effective length $l_{\text {eff }}$ and the feeder transmission coefficient $K$;

$$
\begin{aligned}
& \sigma \psi_{1}^{a}=\left\{\left(K_{\varphi_{1}}^{a} \Delta \varphi\right)^{2}+\left(K_{d_{1}}^{a} \delta d\right)^{2}+\left(K_{s c_{1}}^{a} \delta d_{s c}\right)^{2}\right\}^{\frac{1}{2}} ; \\
& \sigma \psi_{1}^{b}=\left\{\left(K_{\theta_{1}}^{b} \Delta \theta\right)^{2}+\left(K_{\varphi_{1}}^{b} \Delta \varphi\right)^{2}+\left(K_{s c_{1}}^{b} \delta d_{s c}\right)^{2}\right\}^{\frac{1}{2}} ;
\end{aligned}
$$

$K_{\varphi_{1}}^{a}=\sqrt{\left(\alpha_{c}^{a} \sin \gamma_{s c}^{a}\right)^{2}+\left(\gamma_{s}^{a} \cos \gamma_{s c}^{a}\right)^{2}}$ is the sensitivity

factor of the voltage $U_{1}^{a}$ to azimuth error of the source $b ; \quad \alpha_{c}^{a}=k_{a} d \cos \chi \quad$ is derivative of the phase $\alpha_{s}^{a} ; \gamma_{s}^{a}=k_{a} d_{s c} \sin \chi$ is derivative of the phase $\gamma_{s c}^{a}$ with respect to the azimuthal angle; $K_{d_{1}}^{a}=d_{s}^{a} \sin \gamma_{s c}^{a}$ is the sensitivity coefficient of the voltage $U_{1}^{a}$ to the estimation error of the distanced between the phase centers of vibrators; $K_{s c_{1}}^{a}=\gamma_{s c}^{a} \cos \gamma_{s c}^{a}$ is the sensitivity coefficient of the voltage $U_{1}^{a}$ to the estimation error of the distance $d_{s c}$ between the phase centers of vibrators and screen; $K_{\theta_{1}}^{b}=\sin \chi_{\theta} \sin \gamma_{s c}^{b}-\gamma_{s}^{b} \cos \chi_{\theta} \cos \gamma_{s c}^{b}$ is the sensitivity factor of the voltage $U_{1}^{b}$ to an inaccurate setting of the angle $\theta_{a}=90^{\circ} ; \gamma_{s}^{b}=k_{b} d_{s c} \sin \chi_{\theta}$ is derivative of the phase $\gamma_{s c}^{b}$ with respect to the meridional angle; $\quad K_{\varphi_{1}}^{b}=k_{b} d \cos ^{2} \chi_{\theta} \sin \gamma_{s c}^{b}$ is the sensitivity factor of the voltage $U_{1}^{b}$ to the error in the azimuth of the source $b ; K_{s c_{1}}^{b}=\gamma_{s c}^{b} \cos \chi_{\theta} \cos \gamma_{s c}^{b}$ is the sensitivity coefficient of the voltage $U_{1}^{b}$ to the estimation error of the distance between the vibrators and screen.

Instrumental error for the voltage $U_{2}\left(U_{4}\right)$

$$
\begin{aligned}
\sigma U_{2}= & U_{a}^{\varphi}\left\{\left(\sigma T_{1}\right)^{2} \cos ^{2} \chi \sin ^{2} \gamma_{s c}^{a}+\left(\sigma \psi_{2}^{a}\right)^{2}\right\}^{\frac{1}{2}}+ \\
& +U_{b}^{\varphi}\left\{\left(\sigma T_{1}\right)^{2} \sin ^{2} \gamma_{s c}^{b}+\left(\sigma \psi_{2}^{b}\right)^{2}\right\}^{\frac{1}{2}},
\end{aligned}
$$

where

$\sigma \psi_{2}^{a}=\left\{\left(K_{\varphi_{2}}^{a} \Delta \varphi\right)^{2}+\left(\alpha_{s}^{a} \cos \chi \sin \gamma_{s c}^{a} \delta d\right)^{2}+\left(\gamma_{c}^{a} \cos \chi \cos \gamma_{c}^{a} \delta d_{e}\right)^{2}\right)^{\frac{1}{2}} ;$ $K_{\varphi_{2}}^{a}=\sqrt{\left(\alpha_{c}^{a} \cos \chi \sin \gamma_{s c}^{a}\right)^{2}+\left(\sin \chi \sin \gamma_{s c}^{a}+\gamma_{s}^{a} \cos \chi \cos \gamma_{s c}^{a}\right)^{2}}$ is the voltage sensitivity coefficient of the source $a$ to the inaccuracy of the azimuth bearing to the source $b$;

$\sigma \psi_{2}^{b}=\left\{\begin{array}{l}\left(\gamma_{s}^{b} \cos \gamma_{s c}^{b} \Delta \theta\right)^{2}+\left(k_{b} d \cos ^{2} \chi \sin \gamma_{s c}^{b} \Delta \varphi\right)^{2}+ \\ +\left(\gamma_{s c}^{b} \cos \gamma_{s c}^{b} \delta d_{s c}\right)^{2}\end{array}\right\}^{\frac{1}{2}}$ is

RMS error of function $\psi_{2}^{b}$.

Similarly, using equation (4), the errors of the voltages $U_{5}, \ldots, U_{8}$ are found.

Since the amplitudes of the voltages $\dot{U}_{s}$ for $s=\overline{1,8}$ (6) are used by the processor to calculate the parameters of the radiation field, formulas for the voltage errors on the right side should have one more component. That is due to the inaccuracy of setting the transmission coefficient $t_{d}$ of the amplitude detectors. For example, formula (20) takes the form

$$
\begin{aligned}
& \sigma U_{1}=t_{d} U_{a}^{\theta}\left\{\left[\left(\sigma T_{1}\right)^{2}+\left(\sigma t_{d}\right)^{2}\right] \sin ^{2} \gamma_{s c}^{a}+\left(\sigma \psi_{1}^{a}\right)^{2}\right\}^{\frac{1}{2}}+ \\
& +t_{d} U_{b}^{\theta}\left\{\left[\left(\sigma T_{1}\right)^{2}+\left(\sigma t_{d}\right)^{2}\right] \cos ^{2} \chi_{\theta} \sin ^{2} \gamma_{s c}^{b}+\left(\sigma \psi_{1}^{b}\right)^{2}\right\}^{\frac{1}{2}},
\end{aligned}
$$

where $\sigma t_{d}=\Delta t_{d} / t_{d}$ is a relative error of detector transmission coefficient.

Similarly, the expressions for voltages $\dot{U}_{2}, \dot{U}_{3}$ and $\dot{U}_{4}$ are written.

The expression for the error of the voltage $\dot{U}_{5}$ varies as follows 


$$
\begin{aligned}
& \sigma U_{5}=2 t_{d} t_{a d} U_{a}^{\theta} \times \\
& \times\left\{\sin ^{2} \gamma_{s c}^{a}\left[\begin{array}{l}
\left(\delta t_{a d} \cos \alpha_{c}^{a}\right)^{2}+ \\
+\left(\sigma t_{d} \cos \alpha_{c}^{a}\right)^{2}+\left(\sigma T_{1}\right)^{2}
\end{array}\right]+\left(\sigma \psi_{1}^{a}\right)^{2}\right\}^{\frac{1}{2}}+ \\
& +2 t_{d} t_{a d} U_{b}^{\theta}\left\{\left[\begin{array}{l}
\left.\left.\left[\delta t_{a d}\right)^{2}+\left(\delta t_{d}\right)^{2}+\left(\sigma T_{1}\right)^{2}\right] \times\right\}^{\frac{1}{2}} \\
\times \cos ^{2} \chi_{\theta} \sin ^{2} \gamma_{s c}^{b}+\left(\sigma \psi_{1}^{b}\right)^{2}
\end{array}\right\} .\right.
\end{aligned}
$$

Similarly, the inaccuracies in the transmission of detectors in the errors of the voltages $\dot{U}_{6}, \dot{U}_{7}$ and $\dot{U}_{8}$ are taken into account.

In the process of detection, variables can be formed. However, they can be filtered entirely, and their influence can be almost neglected.

In mode $A$, in the presence of noise (source $b$ ) the voltages $\dot{U}_{9}$ and $\dot{U}_{10}(5)$ are used. For the analysis of errors, the values of their amplitudes can be written as:

$$
\left.\begin{array}{c}
\dot{U}_{9}=t_{d}\left|\dot{U}_{9}\right|= \\
=t_{d} \sqrt{\left(t_{a d} U_{5}\right)^{2}+\left(t_{a d} U_{8}\right)^{2}-2\left(t_{a d} U_{5}\right)\left(t_{a d} U_{8}\right) \cos \psi} \\
\dot{U}_{11}=t_{d}\left|\dot{U}_{11}\right|= \\
=t_{d} \sqrt{\left(t_{a d} U_{5}\right)^{2}+\left(t_{a d} U_{8}\right)^{2}+2\left(t_{a d} U_{5}\right)\left(t_{a d} U_{8}\right) \cos \psi},
\end{array}\right\}
$$

where $\psi$ is the phase shift between phases of vectors $\dot{E}_{a}^{\theta} \quad$ and $\quad \dot{E}_{a}^{\varphi} ; \quad U_{5}=2 t_{a d} U_{a}^{\theta} \sin \alpha_{s}^{a} \sin \gamma_{s c}^{a} \quad$ is the amplitude of voltage $\quad \dot{U}_{5}$; $U_{8}=2 t_{a d} U_{a}^{\varphi} \cos \chi \sin \alpha_{s}^{a} \sin \gamma_{s c}^{a}$ is the amplitude of the voltage $\dot{U}_{8}$.

The following notation is introduced to obtain

$$
\left.\begin{array}{c}
U_{9}=2 t_{d} t_{a d}^{2} \sin \alpha_{s}^{a} \sin \gamma_{s c}^{a} U_{a}^{\Delta} ; \\
U_{11}=2 t_{d} t_{a d}^{2} \sin \alpha_{s}^{a} \sin \gamma_{s c}^{a} U_{a}^{\Sigma} ; \\
U_{a}^{\Delta}=\sqrt{\left(U_{a}^{\theta}\right)^{2}+\left(U_{a}^{\varphi} \cos \chi\right)^{2}-2 U_{a}^{\theta} U_{a}^{\varphi} \cos \chi \cos \psi} ; \\
U_{a}^{\Sigma}=\sqrt{\left(U_{a}^{\theta}\right)^{2}+\left(U_{a}^{\varphi} \cos \chi\right)^{2}+2 U_{a}^{\theta} U_{a}^{\varphi} \cos \chi \cos \psi} .
\end{array}\right\}
$$

RMS errors of the voltages $\dot{U}_{9}$ and $\dot{U}_{11}$ are expressed through the coefficient of sensitivity

$$
\begin{aligned}
& \sigma U_{9}=\sqrt{\left(\delta T_{2} U_{9}\right)^{2}+\left(K_{5}^{9} \sigma U_{5}\right)^{2}+\left(K_{8}^{9} \sigma U_{8}\right)^{2}} ; \\
& \sigma U_{11}=\sqrt{\left(\delta T_{2} U_{11}\right)^{2}+\left(K_{5}^{11} \sigma U_{5}\right)^{2}+\left(K_{8}^{11} \sigma U_{8}\right)^{2}},
\end{aligned}
$$

where $\sigma T_{2}=\sqrt{\left(\delta t_{d}\right)^{2}+\left(\delta t_{a d}\right)^{2}}$ is the errors in transmissions of detectors and adders of the LC block of the 2nd level $\left(T_{2}=t_{d} t_{a d}\right) ; K_{5}^{9}=T_{2} \frac{U_{a}^{\theta}-U_{a}^{\varphi} \cos \chi \cos \psi}{U_{a}^{\Delta}}$ is the sensitivity factor of the voltage $U_{9}$ to the instrumental error of the voltage $\dot{U}_{5}$;

$$
K_{8}^{9}=T_{2} \frac{U_{a}^{\varphi} \cos \chi-U_{a}^{\theta} \cos \psi}{U_{a}^{\Delta}} \text { is the sensitivity factor }
$$

of the voltage $U_{9}$ to the error of the voltage $\dot{U}_{8}$; $K_{5}^{11}=T_{2} \frac{U_{a}^{\theta}+U_{a}^{\varphi} \cos \chi \cos \psi}{U_{a}^{\Delta}}$ is the sensitivity factor of the voltage $U_{11}$ to the error of the voltage $\dot{U}_{5}$; $K_{8}^{11}=T_{2} \frac{U_{a}^{\varphi} \cos \chi+U_{a}^{\theta} \cos \psi}{U_{a}^{\Delta}}$ is the sensitivity factor of the voltage $U_{11}$ to the error of the voltage $\dot{U}_{8}$.

On the next step, the received voltage in the mode $A$ with noise is used to calculate the parameters of the electromagnetic field of the source $a$.

The phase shift calculated by the formula

$$
\cos \psi=\frac{U_{11}^{2}-U_{9}^{2}}{4 T_{2}^{2} U_{5} U_{8}}
$$

From this formula, it follows that the error of the trigonometric function is equal to

$$
\sigma(\cos \psi)=\sqrt{\frac{\left(K_{9}^{\psi} \sigma U_{9}\right)^{2}+\left(K_{11}^{\psi} \sigma U_{11}\right)^{2}+}{+\cos ^{2} \psi\left[\left(2 \delta T_{2}\right)^{2}+\left(\sigma U_{5}\right)^{2}+\left(\sigma U_{8}\right)^{2}\right]},}
$$

where $K_{9}^{\psi}=-\frac{U_{9}^{2}}{2 T^{2} U_{5} U_{8}}$ is the sensitivity to change of the voltage $U_{9} ; K_{11}^{\psi}=\frac{U_{11}^{2}}{2 T^{2} U_{5} U_{8}}$ is the sensitivity to change of the voltage $U_{11}$.

The ratio of the meridional component of the field intensity to the azimuthal value is estimated as

$$
m=\frac{U_{5}}{U_{8}} \cos \chi
$$

The mean square error of the ratio $m$ is defined as

$$
\sigma m=m \sqrt{\left(\sigma U_{5}\right)^{2}+\left(\sigma U_{8}\right)^{2}+(\operatorname{tg} \chi \Delta \varphi)^{2}} .
$$

The tangent of the double angle of inclination of the polarization ellipse is equal

$$
\operatorname{tg} 2 \gamma=\frac{2 m \cos \psi}{m^{2}-1}
$$


Using the formula (22) can be found

$$
\sigma \gamma=\frac{m}{\left(m^{2}+1\right)^{2}-4 m^{2} \sin ^{2} \psi}\left\{\begin{array}{l}
\left(m^{2}-1\right)^{2}(\sin \psi \Delta \psi)^{2}+ \\
+\left(m^{2}+1\right)^{2}(\cos \psi \sigma m)^{2}
\end{array}\right\}^{\frac{1}{2}}
$$

Another important polarization parameter is the ellipticity coefficient, which is calculated by the formula

$$
K_{e}=\sqrt{\frac{m \sin ^{2} \gamma-\sin 2 \gamma \cos \psi+\frac{1}{m} \cos ^{2} \gamma}{m \cos ^{2} \gamma+\sin 2 \gamma \cos \psi+\frac{1}{m} \sin ^{2} \gamma} .}
$$

The errors of his calculation are defined as

$$
\sigma K_{e}=\frac{m^{2}+1}{m K_{e} Q^{2}} \sqrt{\left(K_{m}^{e} \sigma m\right)^{2}+\left(K_{\gamma}^{e} \sigma \gamma\right)^{2}+\left(K_{\psi}^{e} \Delta \psi\right)^{2}},
$$

where

$$
Q=m \cos ^{2} \gamma+\sin 2 \gamma \cos \psi+\frac{1}{m} \sin ^{2} \gamma
$$

$K_{m}^{e}=\frac{m^{2}-1}{m\left(m^{2}+1\right)} \sin \gamma \cos \gamma \cos \psi-\frac{1}{m^{2}+1} \cos 2 \gamma \quad$ is the sensitivity of the ellipticity coefficient to the errors of the value $m ; \quad K_{\gamma}^{e}=\frac{m^{2}-1}{m} \sin \gamma \cos \gamma-\cos 2 \gamma \cos \psi$ is the sensitivity of the ellipticity coefficient to the errors of the angle $\gamma ; K_{\psi}^{e}=\sin \gamma \cos \gamma \sin \psi$ is the sensitivity of the ellipticity coefficient to the errors of the angle $\psi$.

Measurement errors of the meridional and azimuthal components of the vector of the electric field intensity are determined from the correlations. This correlations bind magnitudes $E_{a}^{\theta}$ and $E_{a}^{\varphi}$ with the voltages $\dot{U}_{5}$ and $\dot{U}_{8}$, or from the expressions (16) and (17) in modes $B$ and $C$.

According to the formula, which is shown in the work [19], can be written

$$
E_{a}^{\theta}=\frac{U_{5}}{2 T_{1} T_{2} \sin \left(k_{a} d \sin \chi\right) \sin \left(k_{a} d_{s c} \cos \chi\right)} .
$$

Based on this ratio, the RMS value of the absolute error can be obtained

$$
\sigma E_{a}^{\theta}=E_{a}^{\theta}\left\{\begin{array}{c}
\left(\sigma U_{5} / U_{5}\right)^{2}+\left(\sigma T_{1}\right)^{2}+\left(\sigma T_{2}\right)^{2}+ \\
+\left(K_{\chi}^{E} \Delta \varphi\right)^{2}+\left(K_{d}^{E} \delta d\right)^{2}+\left(K_{d_{s c}}^{E} \delta d_{s c}\right)^{2}
\end{array}\right\}^{\frac{1}{2}}
$$

where $K_{\chi}^{E}=\left[k_{a} d \cos \chi \operatorname{ctg}\left(k_{a} d \sin \chi\right)-\right.$ is the sensitivity $\left.-k_{a} d_{s c} \sin \chi \operatorname{ctg}\left(k_{a} d_{s c} \cos \chi\right)\right]$

of the calculation result to the azimuthal angle error; $K_{d}^{E}=k_{a} d \sin \chi \operatorname{ctg}\left(k_{a} d \sin \chi\right)$ is the sensitivity of the calculated value of the field intensity to the errors in the distances between the elements of the antenna array; $K_{d_{s c}}^{E}=k_{a} d_{s c} \cos \chi \operatorname{ctg}\left(k_{a} d_{s c} \cos \chi\right)$ is the sensitivity of the calculated value of the field intensity to the errors in the distances from the vibrator to the screen.

The formula for the azimuthal component of the electric field intensity is written as

$$
E_{a}^{\varphi}=\frac{U_{8}}{2 T_{1} T_{2} \cos \chi \sin \left(k_{a} d \sin \chi\right) \sin \left(k_{a} d_{s c} \cos \chi\right)} .
$$

The error in calculating the azimuthal component of the field intensity is equal to

$$
\sigma E_{a}^{\varphi}=E_{a}^{\varphi}\left\{\begin{array}{c}
\left(\sigma U_{8} / U_{8}\right)^{2}+\left(\sigma T_{1}\right)^{2}+\left(\sigma T_{2}\right)^{2}+ \\
+\left(K_{\chi \varphi}^{E} \Delta \varphi\right)^{2}+\left(K_{d}^{E} \delta d\right)^{2}+\left(K_{d_{s c}}^{E} \delta d_{s c}\right)^{2}
\end{array}\right\}^{\frac{1}{2}}
$$

where the sensitivity coefficient to the errors of the azimuth angle is somewhat different from $K_{\chi}^{E}$, namely $K_{\chi \varphi}^{E}=K_{\chi}-\operatorname{tg} \chi\left[\sin \left(k_{a} d \sin \chi\right) \sin \left(k_{a} d_{s c} \cos \chi\right)\right]^{-1}$.

From the expressions for the sensitivity coefficient $K_{d}^{E}$, it follows that the inaccuracy in the dimension $d$ can limit the resolution of the antenna system.

In the absence of radiation at frequencies that are close to the frequency of the source $a\left(E_{b}=0\right)$, processes in the antenna system differ significantly from methods with interference suppression. In this case the formula (21) is simplified

$$
\sigma m=m \sqrt{\left(\sigma U_{6}\right)^{2}+\left(\sigma U_{7}\right)^{2}}
$$

The remaining polarization parameters and their errors are calculated by the formulas (22), (23), (24) and (25).

The meridional and azimuthal components of the electric field intensity vector can be calculated by the voltages $U_{7}$ and $U_{6}$ :

$$
\left.\begin{array}{l}
E_{a}^{\theta}=\frac{U_{7}}{2 T_{1} T_{2} \sin k d_{s c}} \\
E_{a}^{\varphi}=\frac{U_{6}}{2 T_{1} T_{2} \sin k d_{s c}}
\end{array}\right\}
$$

The mean square error of the estimates of the field intensity components are equal to 




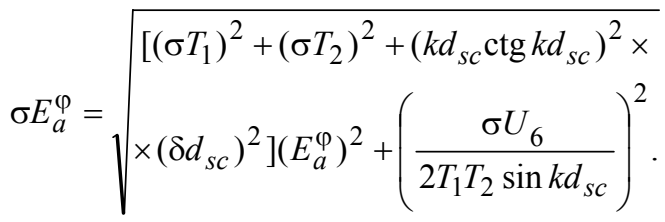

From last formulas it follows that the bandwidth of the antenna system depends primarily on the error $\delta d_{s c}$, that is the accuracy of establishing the distances between the phase centers of the antenna elements and the screen.

\section{EXPERIMENTS}

The Mathcad was used to construct experimental graphs. The study of dependences of measurement errors of polarization parameters was chosen as an example for proving the correctness of the derived relations. For this reason, the above formulas (23), (24), and (25) were used. It was decided in these formulas to fix the next components of the relative and absolute errors in measuring the inclination angle of the polarization ellipse and the ellipticity coefficient. The error in determining the ratio of the meridional component $\dot{E}_{a}^{\theta}$ of the field intensity to the azimuthal $\dot{E}_{a}^{\varphi}$ is $\sigma m=0.01$. This error $\sigma m$, following formula (21), in turn, depends on errors in determining voltages $U_{5}$ and $U_{8}$, angle of separation of radiation sources and error in determining the azimuthal angle in case of operating mode $A . \Delta \psi=1 \mathrm{deg}$ is the error in determining the phase shift between the phases of the vectors $\dot{E}_{a}^{\theta}$ and $\dot{E}_{a}^{\varphi}$. An increase in these components leads to a sharp increase in errors in measuring the polarization parameters and changing like their dependences.

\section{RESULTS}

In Fig. 3 dependences of the error in measuring the angle of inclination of the polarization ellipse on the ratio of the meridional component of the field intensity to the azimuthal value are shown.

To build the dependence of the error in determining the polarization coefficient on the inclination angle of the polarization ellipse (Fig. 4). The error in determining the inclination angle of the polarization ellipse was chosen as $\sigma \gamma=0.5 \operatorname{grad}(\approx 0.009 \mathrm{rad})$. The value of the error in determining the coefficient of ellipticity inadmissibly increases with an increase in this error.

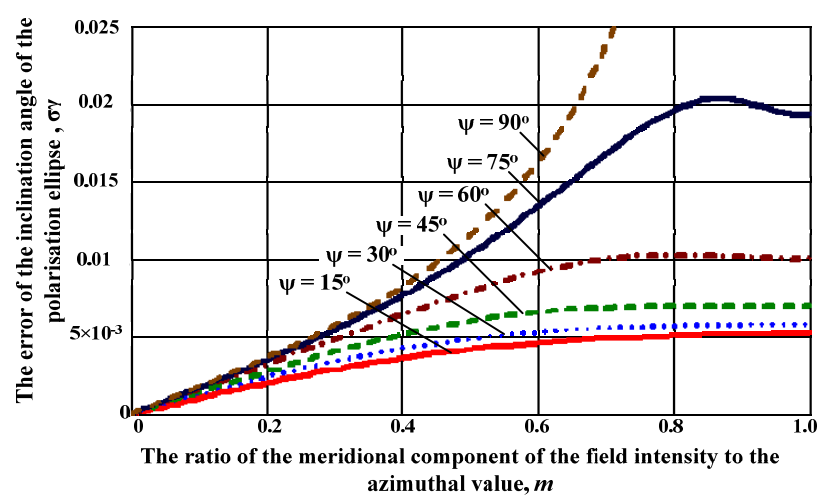

Figure 3 - Dependences of error in measuring the inclination angle of the polarization ellipse on the ratio $m$



Figure 4 - Dependences of error in measuring the polarization coefficient on the inclination angle

\section{DISCUSSION}

From the results of modelling errors in measuring the polarization characteristics of the wave, the following conclusions can be drawn.

From the formula (23) and Fig. 3 it follows that when $\psi=90^{\circ}$ and $m=1$, the error in measuring the inclination angle of the polarization ellipse ${ }^{\sigma \gamma}$ becomes uncertain. Under these conditions, the wave polarization of the understudy becomes circular. Moreover, the angle of inclination $\gamma$ of the polarization ellipse loses its meaning. It was using the formula (25) and graphs in Fig. 4, it can be concluded that when $\gamma=90^{\circ}$ and $m=0$, the measurement error $\sigma K_{e}$ of the ellipticity coefficient also becomes uncertain. In this case, the wave polarization becomes linear, and the ellipticity coefficient $K_{e}$ loses its meaning.

The smallest errors in measuring the polarization parameters are possible for the cases of linear polarization (when measuring the inclination angle of the polarization ellipse) and circular polarization (when measuring the ellipticity coefficient).

Based on the formulas obtained in work, the first level of the linear converter, which is built on linear adders, has the most significant influence on the errors in measuring the parameters of the investigated wave (polarization parameters, components of the electric field intensity). 


\section{CONCLUSIONS}

In summary, this paper argued that the errors of measuring the electromagnetic field parameters by radiomonitoring antenna systems were researched. As an example, the low-element antenna array with a primary signal processing device was chosen. This antenna system provides the essential functions of radiomonitoring include the following: automated space inspection and radiation source detection, automatic determination of the angular coordinates of the radiation sources, interference suppression at frequencies close to the frequency of controlled radio emission, measurement of electric field intensity, measurement of the polarization parameters of the radiation field. The synthesized structural diagram of the antenna system is provided with auto-control circuits, which guarantees timely detection of failures and maintenance of the system in working order, as well as it is functioning within the precision characteristics laid down in the design.

The scientific novelty. In the article, the mathematical model of the antenna system for radiomonitoring stations was built. The mathematical model takes into account the transmission coefficients of the most important structural components. To simplify the determination of instrumental errors, the number of variable informative voltages were limited.

The practical significance. As a result of mathematical analysis, analytical expressions were obtained to assess the influence of structural elements on the accuracy of measurement processes. The dependences of the measurement errors of the main field parameters on the RMS errors of the voltages at each stage of the signal processing in the structural diagram are shown. That makes it possible to accurately determine the circuit node that most affects the measurement error of a specific parameter of the electromagnetic field.

It was found that angular resolution depends not only on the directivity of the antenna array but also on the accuracy of establishing the distances between the phase centres of real and virtual antenna elements. The operating bandwidth of the antenna array is limited not only by the deformation of the pattern but also by the errors of the antenna element design.

Prospects for further research. Future studies could fruitfully explore the accuracy of the antenna system operation further by simulation using MATLAB software. Additionally, an experimental study is planned using different types of elements in the antenna array.

\section{REFERENCES}

1. Ivanov V. O., Gabrusenko Y. I., Ilnitskiy L. Ya., Shcherbyna O. A. Elektromahnitna sumisnist' radioelektronnoyi aparatury: navchal'nyy posibnyk. Kyiv, NAU, 2014, $312 \mathrm{p}$.

2. Morgan D. A Handbook for EMC Testing and Measurement. Stevenage, Institution of Engineering and Technology, 1994, 304 p. DOI: 10.1049/PBEL008E

3. Slobodyanyuk P. V. Blagodarniy V.G. Spravochnik dlya inzhenerov po radiomonitoringu. Kiev, 2012, 720 p.
4. Proesch R. Technical Handbook for Radio Monitoring HF. Norderstedt, Books on Demand GmbH, 2013, 564 p.

5. Proesch R., Daskalaki-Proesch A. Technical Handbook for Radio Monitoring VHF/UHF. Norderstedt, Books on Demand GmbH, 2015, $442 \mathrm{p}$.

6. Ilnitskiy L. Ya., Sibruk L. V., Slobodyanyuk P. V., Blagodarniy V. G. Anteny telekomunikatsiynykh i monitorynhovykh system. Kyiv, Ukrayins'kyy derzhavnyy tsentr radiochastot, 2012, $240 \mathrm{p}$.

7. Balanis C. A. Antenna Theory: Analysis and Design. 4th Edition. New Jersey, John Wiley \& Sons, 2016, 534 p.

8. Haupt R.L. Antenna Arrays: A Computational Approach. New Jersey, John Wiley \& Sons, 2010, 1095 p. DOI: 10.1002/9780470937464

9. Hacene Y., Shuguo X. Study of a Novel Ultra-Wideband Monopole Antenna for EMC Measurement Applications, IEEE 6th Asia-Pacific Conference on Environmental Electromagnetics (CEEM), Shina, 6-9 November, 2012: proceedings. Shanghai, 2012, pp. 393-395. DOI: 10.1109/CEEM.2012.6410651

10. Yang J., Kishk A. A. Two New Types of Compact Ultrawideband Antennas for EMC Measurements / J. Yang, // IEEE International Symposium on Electromagnetic Compatibility (EMC Europe 2014), Sweden, 1-4 September, 2014: proceedings. Gothenburg, 2014, pp. 5-8. DOI: 10.1109/EMCEurope.2014.6930866

11. Chen G.-Yu, Sun J.-S., Huang S.-Yi et al. The Tapered TEM Horn Antenna Design for EMC and Radiation Measurement, IEEE 7th International Symposium on Antennas, Propagation \& EM Theory (ISAPE), China, 2629 October, 2006: proceedings. Guilin, 2006, pp. 1-4. DOI: 10.1109/ISAPE.2006.353353

12. Hou Z., Weimin L., Jian W., Laixuan M. A Novel Small Sized Biconical Broadband Antenna for EMC Test Application, IEEE Circuits and Systems International Conference on Testing and Diagnosis (CAS-ICTD), China, 28-29 April, 2009: proceedings. Chengdu, 2009, pp. 1-4. DOI: 10.1109/CAS-ICTD.2009.4960763

13. Du R., Wang J., Liu F., Zhou Q. An Effective Nulls Control Method, IEEE 3rd International Symposium on Microwave, Antenna, Propagation and EMC Technologies for Wireless Communications (MAPE), China, 27-29 October, 2009: proceedings. Beijing, 2009, pp. 666-668. DOI: 10.1109/MAPE.2009.5355629

14. Ioannides P., Balanis C. A. Uniform Circular and Rectangular Arrays for Adaptive Beamforming Applications, IEEE Antennas and Wireless Propagation Letters, 2005, Vol. 4, No. 1, pp. 351-354. DOI: 10.1109/LAWP.2005.857039

15. Haupt R.L. Adaptively Thinned Arrays, IEEE Transactions on Antennas and Propagation, 2015, Vol. 63, No. 4, pp. 1626-1632. DOI: 10.1109/TAP.2015.2394785

16. Fan X., Xiao S. Q., Wang Y. L. A Novel Symmetric Weighted Thinned Array with Pattern Reconfigurable Antenna to Achieve Wide-Angle Scanning with Low Side Lobe Level, IEEE MTT-S International Microwave Workshop Series on Advanced Materials and Processes for $R F$ and THz Applications (IMWS-AMP), China, 1-3 July, 2015: proceedings. Suzhou, 2015, pp. 1-4. DOI: 10.1109/IMWS-AMP.2015.7324971

17. Ilnitskiy L. Ya., Shcherbina O. A. Antenna system for measuring electromagnetic field parameters, Radioelectronics and Communications Systems, 2014, Vol. 57, No. 1, pp. 50-60. DOI: $10.3103 / \mathrm{S} 073527271401004 \mathrm{X}$ 
18. Ilnitskiy L. Ya., Shcherbyna O. A., Mykhalchuk I. I. Metrological characteristics of antenna system for measuring electromagnetic field parameters, Radioelectronics and Communications Systems, 2016, Vol. 59, No. 3, pp. 141-149. DOI: $10.3103 / \mathrm{S} 0735272716030055$

19. Ilnitsky L., Shcherbyna O., Mykhalchuk I. Antenna System of Radiomonitoring with Advanced Features, IEEE 4th International Conference Methods and Systems of Navigation and Motion Control (MSNMC), Ukraine, 18-20
October, 2016: proceedings. Kyiv, 2016, pp. 67-71. DOI: 10.1109/MSNMC.2016.7783108

20. Ilnitsky L., Shcherbyna O., Mykhalchuk I., Kozhokhina L. The Antenna Array with Ring Elements, Signal Processing Symposium (SPSympo), Poland, 12-14 September, 2017: proceedings. Jachranka Village, 2017, pp. 1-4. DOI: 10.1109/SPS.2017.8053700

Received 19.08.2020 Accepted 21.09.2020.

УДК 621.396 .67

\section{ХАРАКТЕРИСТИКИ ТОЧНОСТІ АНТЕН РАДІОМОНІТОРИНГУ}

Щербина О. А. - канд. техн. наук, доцент кафедри електроніки, робототехніки і технологій моніторингу та інтернету речей, Національний авіаційний університет, Київ, Україна.

Ільницький Л. Я. - д-р техн. наук, професор кафедри радіоелектронних пристроїв та систем, Національний авіаційний університет, Київ, Україна.

Михальчук I. I. - асистент кафедри електроніки, робототехніки і технологій моніторингу та інтернету речей, Національний авіаційний університет, Київ, Україна.

Кожохіна О. В. - канд. техн. наук, доцент кафедри авіоніки, Національний авіаційний університет, Київ, Україна.

\section{АНОТАЦЯ}

Актуальність. Постійне збільшення кількості радіоелектронного обладнання призводить до все більшого ускладнення електромагнітної обстановки. Для забезпечення електромагнітної сумісності потрібен постійний моніторинг, а також розробка якісної універсальної антени для систем радіомоніторингу.

Мета роботи - побудова математичної моделі антенної системи для станцій радіомоніторингу та розрахунок ії основних характеристик точності.

Метод. Найбільш важливими метрологічними характеристиками вимірювального засобу є методична і інструментальна похибки, тобто залежність цих похибок від параметрів конструктивних елементів, на яких будується пристрій обробки сигналів, що інтегрується з антенною решіткою. Отже, потрібно побудувати математичну модель антенної системи, в якій враховані були б не ідеалізовані, а реальні коефіцієнти передачі найбільш важливих конструктивних складових. Крім того, для забезпечення прозорих функціональних зв'язків між напругами в математичній моделі слід обмежити кількість змінних інформативних напруг. При такому підході визначення інструментальних похибок суттєво спроститься і аналітичні вирази стануть більш придатними для оцінки впливу конструктивних елементів на точність вимірювальних процесів.

Результати. Отримані аналітичні співвідношення, які розкривають вплив різних елементів і схем пристрою на точність вимірювання параметрів полів випромінювань.

Висновки. Представлена антенна система забезпечує вимірювання основних параметрів поля випромінювання як в умовах задовільної електромагнітної обстановки, так і в умовах, коли на частоті корисного сигналу діє інше джерело випромінювання. Кутова розрізнювальна здатність, тобто можливість виокремлювати сигнали при незначних кутових рознесеннях джерел сигналу і завади залежить не тільки від характеристики спрямованості антенної решітки, але й від точності встановлення відстаней між фазовими центрами реальних і віртуальних вібраторів. Робочий діапазон частот антенної решітки обмежується не лише деформацією діаграми спрямованості, але і похибками виконання конструктивних елементів антени.

КЛЮЧОВІ СЛОВА: системи радіомоніторингу, антенна решітка, характеристики точності, методичні помилки, інструментальні помилки.

УДК 621.396 .67

\section{ХАРАКТЕРИСТИКИ ТОЧНОСТИ АНТЕНН РАДИОМОНИТОРИНГА}

Щербина О. А. - канд. техн. наук, доцент кафедры электроники, робототехники и технологий мониторинга и интернета вещей, Национальный авиационный университет, Киев, Украина.

Ільницький Л. Я. - д-р техн. наук, профессор кафедры радиоэлектронных приборов и систем, Национальный авиационный университет, Киев, Украина.

Михальчук I. I. - ассистент кафедры электроники, робототехники и технологий мониторинга и интернета вещей, Национальный авиационный университет, Киев, Украина.

Кожохіна О. В. - канд. техн. наук, доцент кафедры авионики, Национальный авиационный университет, Киев, Украина.

\section{АННОТАЦИЯ}

Актуальность. Постоянное увеличение количества радиоэлектронных средств ведет к все большему усложнению электромагнитной обстановки. Это требует постоянного мониторинга для обеспечения электромагнитной совместимости, а также разработки универсальных антенных систем радиоконтроля.

Цель работы - построение математической модели антенной системы для станций радиомониторинга и расчет ее основных характеристик точности.

Метод. Наиболее важными метрологическими характеристиками измерительного средства являются методическая и инструментальная погрешности, то есть зависимость этих погрешностей от параметров конструктивных элементов устройства обработки сигналов, которое интегрируется с антенной решеткой. Следовательно, математическая модель 
антенной системы должна учитывать не идеализированные, а реальные коэффициенты передачи наиболее важных конструктивных составляющих. Кроме того, для обеспечения прозрачных функциональных связей между напряжениями в математической модели было ограничено количество переменных информативных напряжений. При таком подходе определения инструментальных погрешностей существенно упрощается и аналитические выражения станут более пригодными для оценки влияния конструктивных элементов на точность измерительных процессов.

Результаты. Получены аналитические соотношения, которые раскрывают влияние различных элементов и цепей прибора на точность измерений параметров полей излучений.

Выводы. Представленная антенная система обеспечивает измерение основных параметров поля излучения как в условиях удовлетворительной электромагнитной обстановки, так и в условиях, когда на частоте полезного сигнала действует другой источник излучения. Угловая разрешающая способность, то есть возможность выделять сигналы при незначительных угловых разнесения источников сигнала и помехи, зависит не только от характеристики направленности антенной решетки, но и от точности установления расстояний между фазовыми центрами реальных и виртуальных вибраторов. Рабочий диапазон частот антенной решетки ограничивается не только деформацией диаграммы направленности, но и погрешностями выполнения конструктивных элементов антенны.

КЛЮЧЕВЫЕ СЛОВА: системы радиомониторинга, антенная решетка, характеристики точности, методические ошибки, инструментальные ошибки.

\section{ЛІТЕРАТУРА / ЛИТЕРАТУРА}

1. Електромагнітна сумісність радіоелектронної апаратури: навчальний посібник / [В. О. Іванов, С. І. Габрусенко, Л. Я. Ільницький, О. А. Щербина]. - К. : НАУ, 2014. $312 \mathrm{c}$.

2. Morgan D. A Handbook for EMC Testing and Measurement / D. Morgan. - Stevenage: Institution of Engineering and Technology, 1994. - 304 p. DOI: 10.1049/PBEL008E

3. Слободянюк П. В. Справочник для инженеров по радиомониторингу / П. В. Слободянюк, В. Г. Благодарный. - Киев, 2012. - 720 с.

4. Proesch R. Technical Handbook for Radio Monitoring HF / R. Proesch. - Norderstedt: Books on Demand $\mathrm{GmbH}$, 2013. -564 p.

5. Proesch R. Technical Handbook for Radio Monitoring VHF/UHF / R. Proesch, A. Daskalaki-Proesch. Norderstedt: Books on Demand GmbH, 2015. - 442 p.

6. Антени телекомунікаційних і моніторингових систем / [Л. Я. Ільницький, Л. В. Сібрук, П. В. Слободянюк, В. Г. Благодарный]. - К. : Український державний центр радіочастот, 2012. - $240 \mathrm{c}$.

7. Balanis C. A. Antenna Theory: Analysis and Design. 4th Edition / C. A. Balanis. - New Jersey : John Wiley \& Sons, 2016. $-534 \mathrm{p}$.

8. Haupt R.L. Antenna Arrays: A Computational Approach / R. L. Haupt. - New Jersey: John Wiley \& Sons, 2010. 1095 p. DOI: $10.1002 / 9780470937464$

9. Hacene Y. Study of a Novel Ultra-Wideband Monopole Antenna for EMC Measurement Applications / Y. Hacene, $X$. Shuguo // IEEE 6th Asia-Pacific Conference on Environmental Electromagnetics (CEEM), Shina, 6-9 November, 2012: proceedings. - Shanghai, 2012. - P. 393395. DOI: 10.1109/CEEM.2012.6410651

10. Yang J. Two New Types of Compact Ultra-wideband Antennas for EMC Measurements / J. Yang, A. A. Kishk // IEEE International Symposium on Electromagnetic Compatibility (EMC Europe 2014), Sweden, 1-4 September, 2014: proceedings. - Gothenburg, 2014. - P. 58. DOI: 10.1109/EMCEurope.2014.6930866

11. The Tapered TEM Horn Antenna Design for EMC and Radiation Measurement / [G.-Yu Chen, J.-S. Sun, S.-Yi Huang, et al.] // IEEE 7th International Symposium on Antennas, Propagation \& EM Theory (ISAPE), China, 2629 October, 2006: proceedings. - Guilin, 2006. - P. 1-4 DOI: 10.1109/ISAPE.2006.353353

12. A Novel Small Sized Biconical Broadband Antenna for EMC Test Application / [Z. Hou, L. Weimin, W. Jian, M. Laixuan] // IEEE Circuits and Systems International Conference on Testing and Diagnosis (CAS-ICTD), China,
28-29 April, 2009: proceedings. - Chengdu, 2009. - P. 1-4. DOI: $10.1109 /$ CAS-ICTD.2009.4960763

13. An Effective Nulls Control Method / [R. Du, J. Wang, F. Liu, Q. Zhou] // IEEE 3rd International Symposium on Microwave, Antenna, Propagation and EMC Technologies for Wireless Communications (MAPE), China, 27-29 October, 2009: proceedings. - Beijing, 2009. - P. 666-668. DOI: 10.1109/MAPE.2009.5355629

14. Ioannides P. Uniform Circular and Rectangular Arrays for Adaptive Beamforming Applications / P. Ioannides, C. A. Balanis // IEEE Antennas and Wireless Propagation Letters. - 2005, Vol. 4, № 1. - P. 351-354. DOI: 10.1109/LAWP.2005.857039

15. Haupt R.L. Adaptively Thinned Arrays / R. L. Haupt // IEEE Transactions on Antennas and Propagation. - 2015, Vol. 63, № 4. - P. 1626-1632. DOI: 10.1109/TAP.2015.2394785

16. A Novel Symmetric Weighted Thinned Array with Pattern Reconfigurable Antenna to Achieve Wide-Angle Scanning with Low Side Lobe Level / [X. Fan, S. Q. Xiao, Y. L. Wang] // IEEE MTT-S International Microwave Workshop Series on Advanced Materials and Processes for RF and THz Applications (IMWS-AMP), China, 1-3 July, 2015: proceedings. - Suzhou, 2015. - P. 1-4. DOI: 10.1109/IMWS-AMP.2015.7324971

17. Antenna system for measuring electromagnetic field parameters / L. Ya. Ilnitskiy, O. A. Shcherbina //. Radioelectronics and Communications Systems. - 2014, Vol. 57, № $1 . \quad-\quad$ P. 50-60. DOI: 10.3103/S073527271401004X

18. Metrological characteristics of antenna system for measuring electromagnetic field parameters [L. Ya. Ilnitskiy, O. A. Shcherbyna, I. I. Mykhalchuk] // Radioelectronics and Communications Systems. - 2016, Vol. 59, № 3. - P. 141-149. DOI: 10.3103/S0735272716030055

19. Antenna System of Radiomonitoring with Advanced Features / [L. Ilnitsky, O. Shcherbyna, I. Mykhalchuk] // IEEE 4th International Conference Methods and Systems of Navigation and Motion Control (MSNMC), Ukraine, 18-20 October, 2016: proceedings. - Kyiv, 2016. - P. 6771. DOI: 10.1109/MSNMC.2016.7783108

20. The Antenna Array with Ring Elements / [L. Ilnitsky, O. Shcherbyna, I. Mykhalchuk, L. Kozhokhina] // Signal Processing Symposium (SPSympo), Poland, 12-14 September, 2017: proceedings. - Jachranka Village, 2017. - P. 1-4. DOI: 10.1109/SPS.2017.8053700 